\title{
Effects of pioglitazone therapy on blood parameters, weight and BMI: a meta-analysis
}

\author{
Elena Filipova ${ }^{1 *} \mathbb{0}$, Katya Uzunova ${ }^{1}$, Krassimir Kalinov² and Toni Vekov ${ }^{3}$
}

\begin{abstract}
Background: Type 2 diabetes mellitus (T2DM) is one of the most common diseases worldwide and insulin insufficiency and insulin resistance are two main metabolic issues connected with it. The dyslipidemia associated with insulin resistance and T2DM is characterized by higher triglycerides (TGs), higher very-low-density lipoprotein cholesterol and lower apo A1. Pioglitazone, a member of the thiazolidinedione class, with a proven antihyperglycemic effect, is known to positively influence insulin sensitivity and $\beta$-cell function and to have the potential to alter the lipid profile.

Methods: The aim of our meta-analysis is to summarize and determine the influence of pioglitazone on the glycemic profile and lipoprotein metabolism as well as on weight and BMI in order to highlight the benefit of pioglitazone therapy in patients with T2DM. A comprehensive literature search was conducted through the electronic databases PubMed, MEDLINE, Scopus, PsyInfo, eLIBRARY.ru (from 2000 until February 2016) to identify studies that investigate the effect of pioglitazone on the glycemic and lipid profile and on the weight and BMI. We chose the random-effects method as the primary analysis. Forest plots depict estimated results from the studies included in the analysis and funnel plots are used to evaluate publication bias. Sensitivity analyses were performed in order to evaluate the degree of influence of the consequent elimination of each individual study on the final result.

Results: Of the 1536 identified sources only 15 randomised trials were included in the meta-analysis. Pioglitazone treatment was associated with improvement in the glycemic profile. It reduced FPG levels by a mean of $1.1-2 \mathrm{mmol} / \mathrm{I}$ and $\mathrm{HbA1}$ c by a mean of $0.9-1.3 \%$. Our results reaffirmed the hypothesis that pioglitazone has a positive influence on the lipid profile of T2DM patients with increase in TC and HDL, no significant changes in LDL and notable decrease in TGs. Results also showed that pioglitazone therapy led to increase in both weight and BMI (WMD 1.755, 95\% Cl 0.674 to 2.837 and $1.145,95 \% \mathrm{Cl} 0.389$ to 1.901 respectively).
\end{abstract}

Conclusion: Our results prove that the PPAR $y$ agonist pioglitazone has the potential to be beneficial to patients with T2DM.

Keywords: Pioglitazone, Glycemic profile, Lipid profile, Weight, BMI

\section{Background}

Type 2 diabetes mellitus (T2DM) is one of the most common diseases worldwide. It is a chronic, metabolic disease characterized by elevated levels of blood glucose, which leads to serious damages to many organs over time. In the past three decades the prevalence of T2DM has risen dramatically in countries of all income levels. World health organization (WHO) statistics showed

\footnotetext{
*Correspondence: e.filipova.hq@tchaikapharma.com

1 Science Department, Tchaikapharma High Quality Medicines Inc., 1 G.M. Dimitrov Blvd, 1172 Sofia, Bulgaria

Full list of author information is available at the end of the article
}

that there are about 60 million people with diabetes in the European Region, or about $10.3 \%$ of men and $9.6 \%$ of women aged 25 years and over [1].

Insulin insufficiency and insulin resistance are two main metabolic issues connected with the development of type 2 diabetes. Approximately $92 \%$ of patients with type 2 diabetes demonstrate insulin resistance $[2,3]$. The dyslipidemia associated with insulin resistance and type 2 diabetes is characterized by higher triglycerides, higher very-low-density lipoprotein (VLDL) cholesterol, lower apo A1, and higher low-density lipoprotein (LDL) particle scores. Diabetes was not associated with elevated 
LDL cholesterol levels, potentiation of atherogenesis and cardiac dysfunction occurs in the presence of early diabetic symptoms [3-5].

The thiazolidinediones are a class of antidiabetic drugs that exert their action by binding to the peroxisome proliferator-activated receptor gamma (PPAR- $\gamma$ ) [6]. Pioglitazone, a member of this class, with a proven antihyperglycemic effect, is known to positively influence insulin sensitivity and $\beta$-cell function and to have the potential to alter the lipid profile $[7,8]$. In contrast to the benefits mentioned previously, many authors associate pioglitazone with a significant increase in weight and body mass index (BMI) in patients with T2DM [9-12].

Although the advantages of pioglitazone are well known and outweigh the risks associated with its use many clinicians prefer to prescribe other antihypertensive agents instead. The aim of our meta-analysis is to summarize and determine the influence of pioglitazone on the glycemic profile and lipoprotein metabolism as well as on weight and BMI in order to highlight the benefit of pioglitazone therapy in patients with T2DM.

\section{Methods}

The rationale of this meta-analysis is to determine the effect of pioglitazone therapy on the glycemic and lipid profile in patients with T2DM or impaired glucose tolerance. A comprehensive literature search was conducted through the electronic databases (from 2000 until February 2016) PubMed, MEDLINE, Scopus, PsyInfo, eLIBRARY.ru, as well as registries for data of clinical trials (http://ClinicalTrials.gov and http://www.clinicaltrialsregister.eu) to identify studies that investigate the effect of pioglitazone on the glycemic and lipid profile and on the weight and BMI. The following key words and various combinations were used for the search: pioglitazone; fasting plasma glucose (FBG); glycated hemoglobin (HbA1c); total cholesterol (TC); high-density lipoprotein (HDL); low-density lipoprotein (LDL); triglycerides (TGs); BMI; and weight. Full text articles and abstracts in English and Russian were checked for relevance to the topic and were assessed on the basis of the following inclusion criteria: (1) randomised controlled trials investigating one or more different doses of pioglitazone; (2) determination of changes in the following parameters: FPG, HbA1c, TC, HDL, LDL, TGs, weight and/or BMI throughout treatment with pioglitazone; (3) pioglitazone alone or in combination with any other antidiabetic regimen compared to placebo or active comparators (4) patients with T2DM or impaired glucose tolerance. Any other concomitant conditions related to impaired glucose tolerance or insulin resistance were not considered criteria for exclusion. Inquires were made through contact with authors for any unpublished data, additional unpublished studies or clarifications of methodologies and data included in published articles.

All relevant studies identified were carefully reviewed, sorted, and assessed. Figure 1 depicts the process of selection applied to evaluated studies in order to determine their eligibility for inclusion in the analysis. Extracted data encompassed publication year, duration of treatment, number of patients, FPG (mmol/l), HbA1c (\%), TC (mmol/l), LDL (mmol/l), HDL ( $\mathrm{mmol} / \mathrm{l})$, TGs $(\mathrm{mmol} / \mathrm{l}), \mathrm{BMI}\left(\mathrm{kg} / \mathrm{m}^{2}\right)$, weight $(\mathrm{kg})$. Data for all blood parameters as well as BMI and weight was presented as weighed mean difference with a $95 \%$ confidence interval (CI).

Due to the significant heterogeneity of the individual studies we chose the random-effects method as the primary analysis. To assess the aforementioned heterogeneity of treatment effect among trials, we used the Cochran $\mathrm{Q}$ and the I2 statistics, where $\mathrm{p}$ values of less than 0.10 were used as an indication of the presence of heterogeneity and an I2 parameter greater than 50\% was considered indicative of substantial heterogeneity. The threshold for statistical significance was set at 0.05 . Forest plots depict estimated results from the studies included in the analysis. Funnel plots were used to evaluate publication bias (not shown in the main manuscript, but provided as Additional file 1). Sensitivity analyses were performed in order to evaluate the degree of influence of the consequent elimination of each individual study on the final result. Calculations were made with

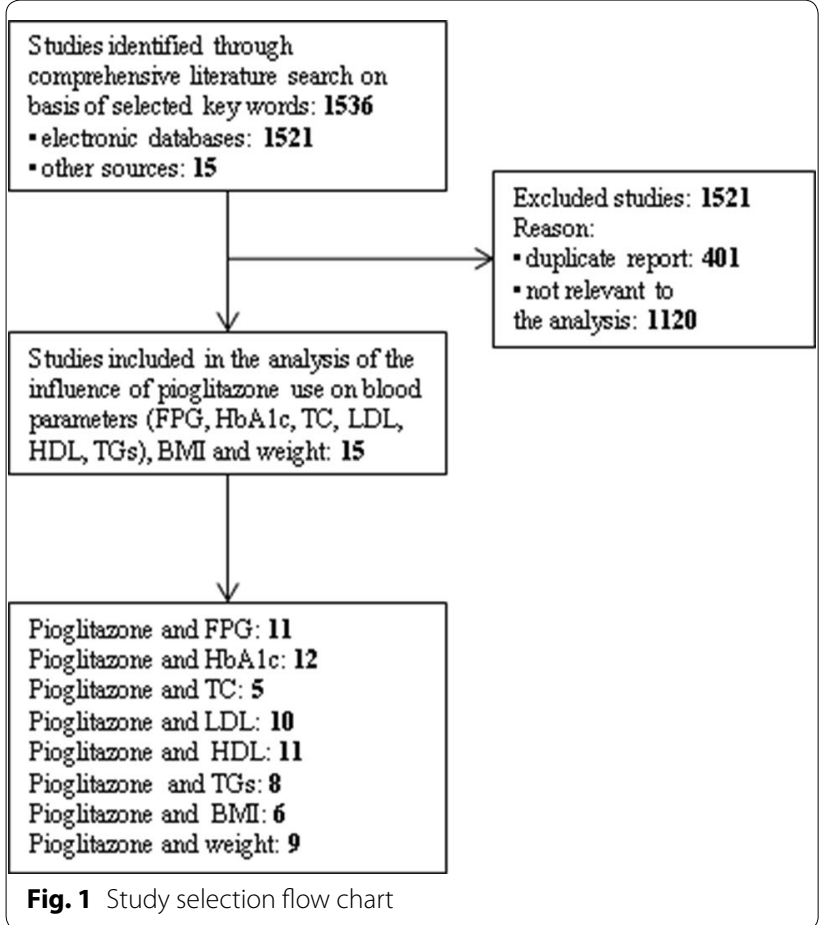


language for statistical modeling $\mathrm{R}$ and MetaXL macro (add-ins of MSExel).

\section{Results}

A large number of studies were identified in the initial search-1536 titles. After evaluation based on the inclusion criteria described in the methods, only 15 studies remained to be included in the analysis of the influence of pioglitazone on blood parameters, BMI and weight (Fig. 1).

Characteristics of the studies included in the metaanalysis are outlined in Table 1. Trial duration lasted from 12 up to 112 weeks. Seven trials were randomised placebo controlled trials [13-18, 24], five trials compared pioglitazone with different antidiabetic treatment $[3,12$, $20,23,25]$, and three trials examined the effect of different doses of pioglitazone (from the lowest concentration to the highest) [19, 21, 22].

Mattoo et al. [15], Berhanu et al. [13], Shah et al. [24] and Rosenstock et al. [18] investigated the metabolic effects of pioglitazone as an add-on treatment to insulin by determining HbA1c, FPG, HDL, LDL and TGs. Belfort et al. [14] examined pioglitazone's effect over nonalcoholic steatohepatitis. DeFronzo et al. [16, 17] contemplated the use of pioglitazone for T2DM prevention in IGT and its influence on $\beta$-cell function. Davidson et al. [19], Gerber et al. [21] and Panikar et al. [22] discussed the dose related response to pioglitazone. Active comparator studies by Goldberg et al. [3], Bolli et al. [12], $\mathrm{Xu}$ et al. [20] and Yoshii et al. [25] compared the effect of pioglitazone to that of rosiglitazone, vildagliptin, exenatide and insulin, and other antihyperglycemic drugs, respectively. Kodama et al. [23] evaluated visceral fat metabolism in patients with impaired glucose tolerance or T2DM treated with pioglitazone.

The 15 studies that satisfied the inclusion criteria were included in the analysis of the influence of pioglitazone on the glycemic and lipid profile of patients with T2DM as well as on changes in weight and BMI. Pooled results showed that pioglitazone use was associated with an increased likelihood for improvement in the following blood parameters: FPG, HbA1c, HDL, LDL. Changes in TC and TGs were not statistically significant while weight and BMI increase significantly (Table 2).

\section{Pioglitazone and glycemic profile}

Figure 2 depicts the estimated effect of pioglitazone on the glycemic profile in T2DM patients. A total of eleven studies [3, 12-21] reporting data for 4812 patients of whom 2859 were treated with pioglitazone were used to estimate the effects of pioglitazone therapy on FPG levels. The pooled results provided a WMD of -1.542 with a $95 \%$ CI $(-1.976$; -1.108$)$ suggesting a significant decrease in FPG values (Fig. 2a). Results from twelve studies [3, 12-15, 18-24] with 2630 pioglitazone treated patients provided evidence for the effects of pioglitazone therapy on HbA1c levels. The summary WMD was -1.086 with $95 \%$ CI $(-1.289$; -0.884$)$ (Fig. 2b). These results speak in favor of the positive impact of pioglitazone therapy with a significant reduction in HbA1c. All in all, pioglitazone treatment was associated with improvement in the glycemic profile. It reduced FPG levels by a mean of $1.1-2 \mathrm{mmol} / \mathrm{l}$ and HbA1c by a mean of $0.9-1.3 \%$.

\section{Pioglitazone and lipid profile}

Data from five studies $[3,13,14,20,21]$ with 884 patients treated with pioglitazone and 797 controls were used in the estimation of the effect of pioglitazone on TC levels. Pooled results showed a slight increase in TC levels WMD $0.128(0.013 ; 0.24)$ (Fig. 3a). A total of 10 studies $[3,13-15,18-21,23,25]$ presenting data for 2334 pioglitazone users produced a WMD $0.055(-0.033 ; 0.142)$ in LDL levels designating a non significant change compared to baseline (Fig. 3b). Results from 11 studies [3, 13-16, 18-21, 23, 25] providing data for 2637 pioglitazone treated patients were pooled to estimate the effect of pioglitazone on HDL levels. WMD 0.190 (0.064; 0.316) showed that HDL levels increased in pioglitazone treated patients (Fig. 3c). Pooled WMD from 8 studies [3, 13, $14,16,18-21]$ investigating the effect of pioglitazone on TGs demonstrated its tendency to decrease TGs levels compared to baseline (Fig. 3d). Our results reaffirm the hypothesis that pioglitazone has a positive influence on the lipid profile of T2DM patients with increase in TC and HDL, no significant changes in LDL and notable decrease in TGs.

\section{Pioglitazone, weight and BMI}

Nine studies $[3,12,14,16,20-24]$ and 6 studies $[14,16$, $17,20,22,24]$ were evaluated in the determination of the effect of pioglitazone on the weight and BMI in T2DM patients, respectively. Results showed that pioglitazone therapy led to increase in both weight and BMI (WMD $1.755,95 \%$ CI 0.674 to 2.837 and $1.145,95 \%$ CI 0.389 to 1.901 respectively) (Fig. 4a, b).

\section{Sensitivity analysis}

The results from the statistical analyses for all studies in relation to the investigated blood parameters, weight and BMI are summarized and presented in Table 3. When each study was subsequently excluded from the analysis, pooled WMD for FPG are in the range -1.678 to -1.462 and for HbA1c -1.138 to -1.041 . The lack of substantial changes in WMD suggests consistency of our findings and confirms the positive effect of pioglitazone 


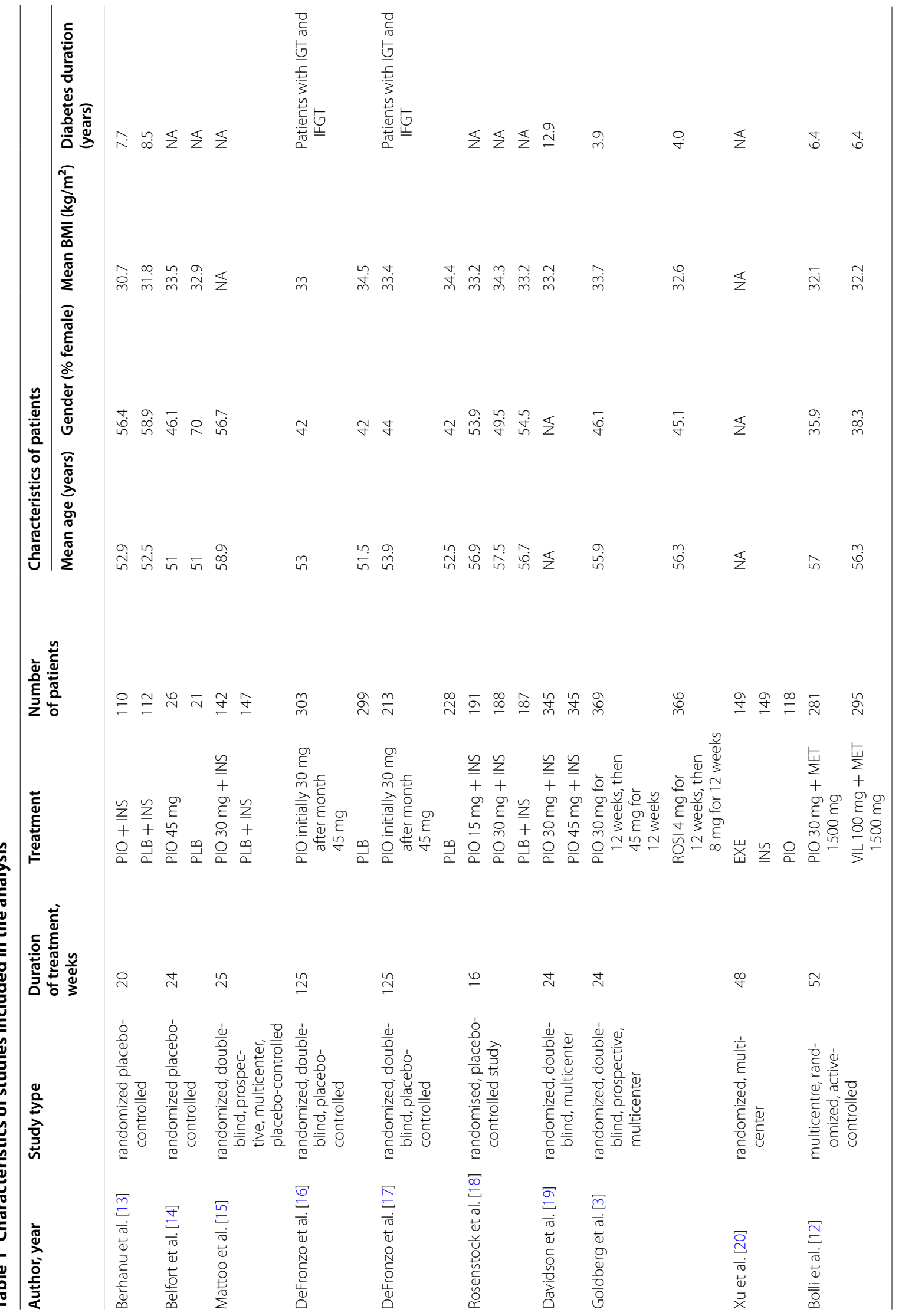




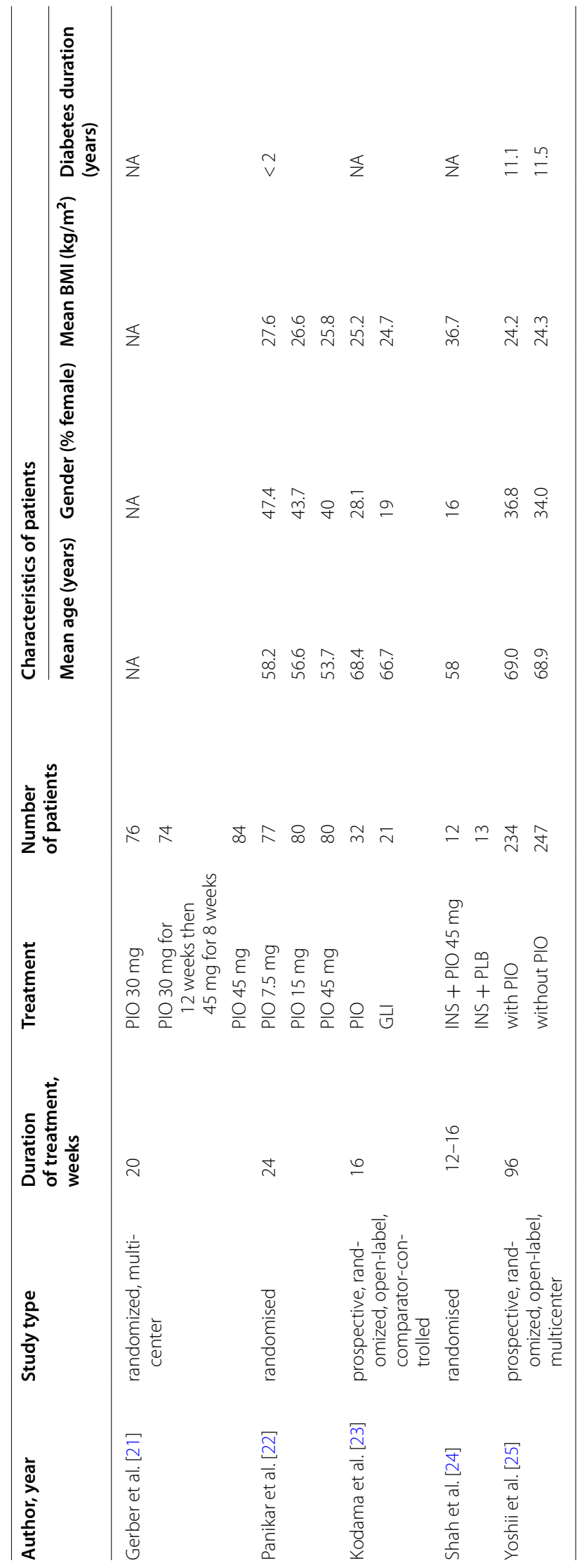




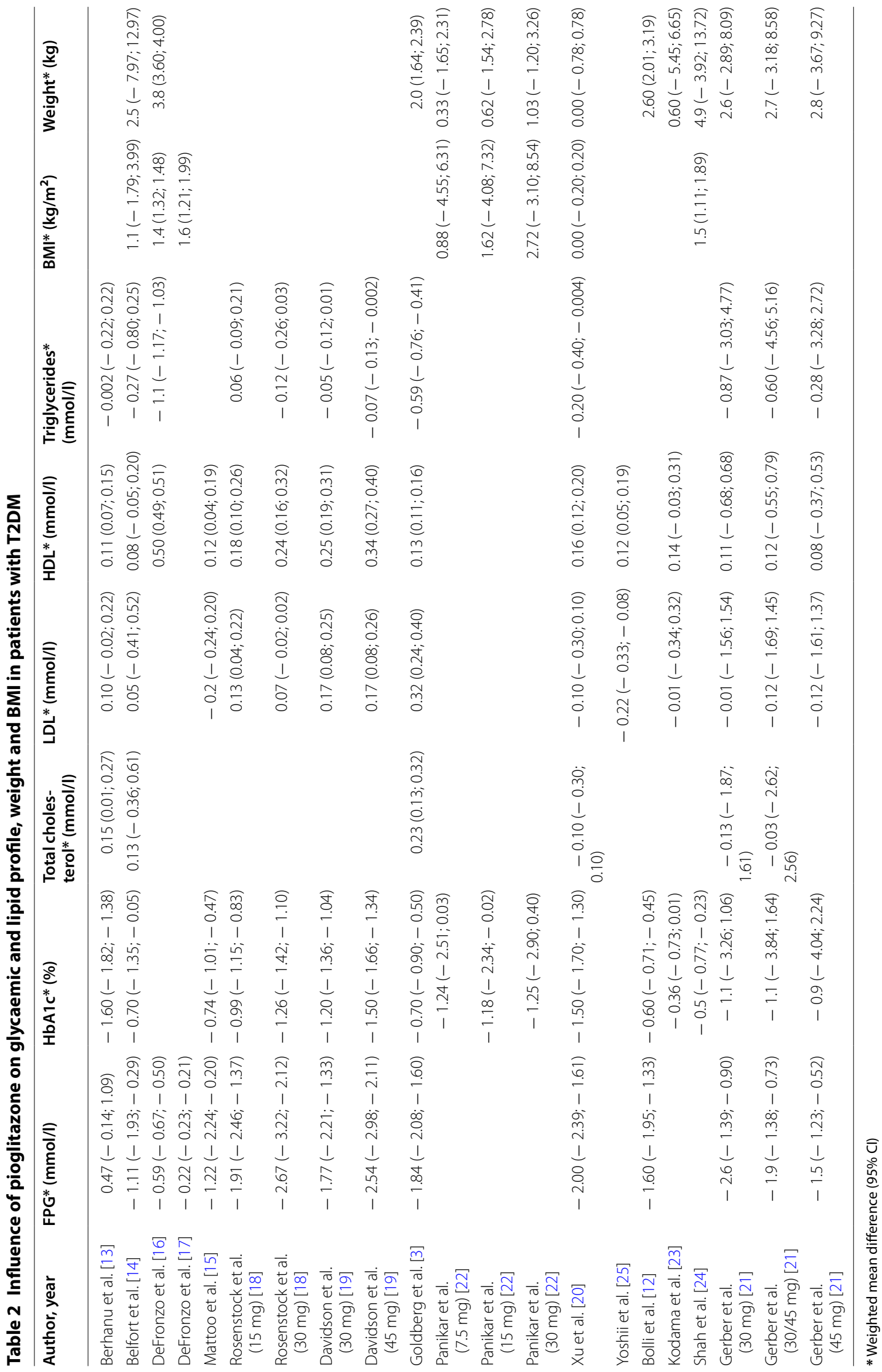




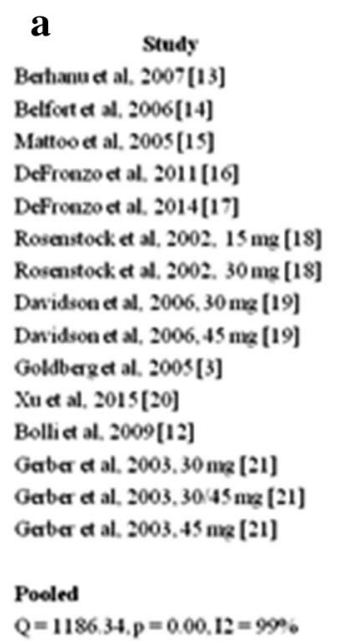

b

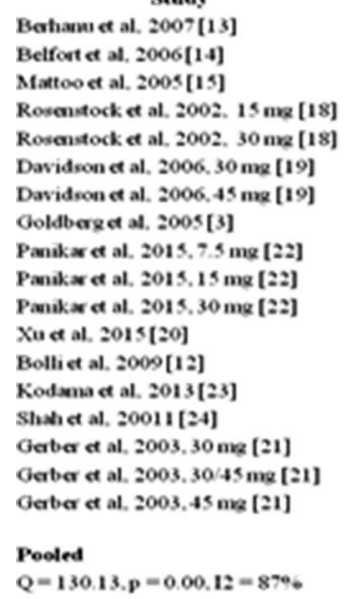

\begin{tabular}{|c|c|c|}
\hline WMD & $95 \% \mathrm{Cl}$ & Wedghto \\
\hline 0.470 & $(-0.140,1.090)$ & 6319 \\
\hline-1.110 & $(-1.930,-0.290)$ & 5.751 \\
\hline-1.220 & $(-2.240,-0.200)$ & 5.17 \\
\hline .0 .590 & $(-0.670,-0.500)$ & 7.219 \\
\hline-0.220 & $(-0.230,-0.210)$ & 7.239 \\
\hline-1.910 & $(-2.460 .-1.370)$ & 6.497 \\
\hline-2.670 & $(-3.220,-2.120)$ & 6.484 \\
\hline-1.770 & $(-2.210,-1.330)$ & 6.737 \\
\hline .2 .540 & $(-2980, .2 .110)$ & 6.748 \\
\hline-1.840 & $(-2.080,-1.600)$ & 7.082 \\
\hline$\cdot 2000$ & $(-2390, .1 .610)$ & 6.839 \\
\hline-1.600 & $(-1.950 .-1.330)$ & 6981 \\
\hline-2600 & $(-1,390,-0.900)$ & 7.075 \\
\hline -1.900 & $(-1.380,-0.730)$ & 6.956 \\
\hline-1.500 & $(-1.230,-0.520)$ & 6.904 \\
\hline-1.242 & $(-1.976 ;-1.105)$ & 100.000 \\
\hline
\end{tabular}

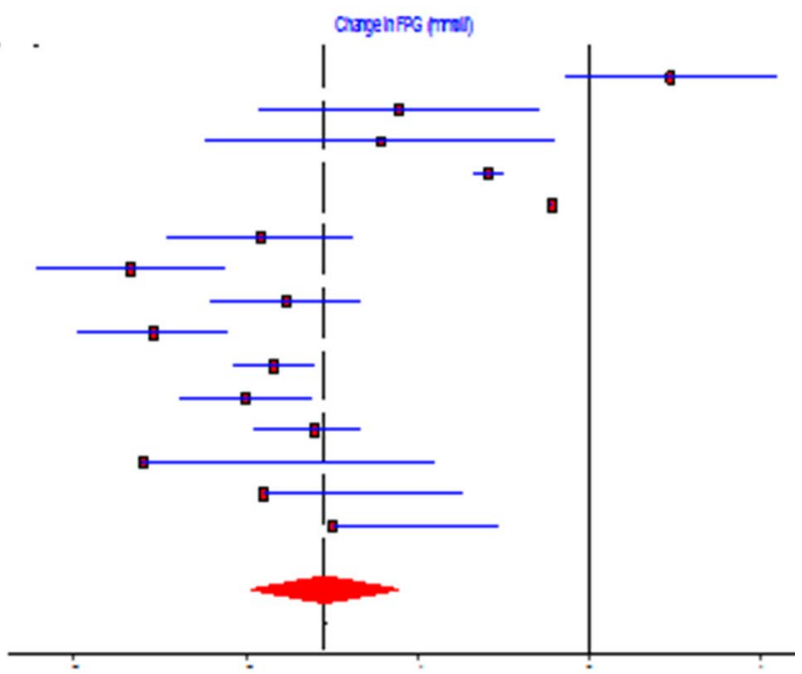
WMII
$-1600 \quad(-1820 ;-1380)$ W 8085
$-0.700 \quad(-1.350,-0.090) \quad 4694$
$.0 .740 \quad(-1.010 ; .0 .470) \quad 7.713$
$-0.990 \quad(-1.150 ;-0.830) \quad 8.466$
$.1 .260 \quad(.1 .420,-1.100) \quad 8460$
$-1.200 \quad(-1.360 ;-1.040) \quad 8.466$
$-1.500 \quad(-1.600,-1.340) \quad 8460$
$-0,700 \quad(-0,900 ;-0,500) \quad 8221$
$\begin{array}{rrr}-1.240 & (-2.510 .0 .030) & 1.980\end{array}$
$-1.180 \quad(-2.340 ;-0.020) \quad 2.273$
$-1.250 \quad(-2.900,0400) \quad 1.280$
$-1.500 \quad(-1.700 ;-1.300) \quad 8.21$
$-1.600 \quad(-1.950,-1.330) \quad 7.390$
$-0.360 \quad(-0.730 .0010) \quad 6884$
$-0.500 \quad(-0.770,-0.230) \quad 7.713$
$\begin{array}{rrr}-1.100 & (-3.260,1.060) & 0.800\end{array}$
$-1.100 \quad(-3.840,1640) \quad 0515$
$-0.900 \quad(-4.040,2.240) \quad 0.398$
-1.086 (-1.289:-0.854) 100.000

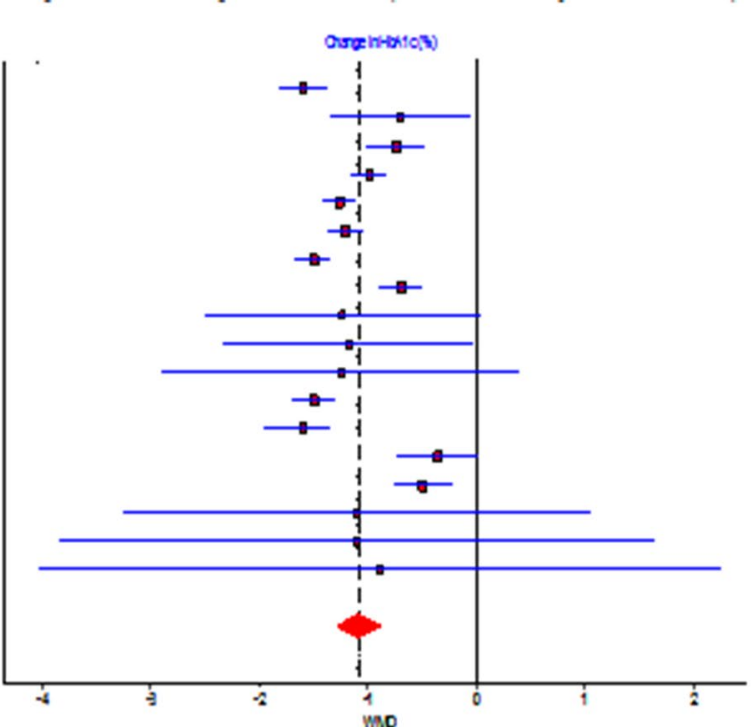

Fig. 2 Influence of pioglitazone on the glycemic profile in T2DM patients, a influence of pioglitazone on the FPG; $\mathbf{b}$ influence of pioglitazone on the $\mathrm{HbAlc}$

on the glycemic profile. When parameters measured in order to estimate the influence of pioglitazone on the lipid profile are subjected to sensitivity analysis pooled WMD for TC is in the range 0.077 to 0.199 , for LDL0.024 to 0.088 , for HDL- 0.172 to 0.199 and for TGs: -0.300 to -0.136 . They confirm our findings and signify of positive effect of pioglitazone on the lipid profile. Pooled results for BMI and weight also suggest consistency of our findings.

\section{Discussion}

TZDs as a whole and pioglitazone in particular are known to favorably influence the majority of the components of insulin resistance characteristic of T2DM, like adiposity, dyslipidaemia, hyperglycaemia, hypertension, cardiovascular abnormalities, hyper coagulation, vasculopathy, accelerated atherosclerosis, and changes in liver and ovaries [26]. A lot of authors conclude that pioglitazone successfully reduces $\mathrm{HbA} 1 \mathrm{c}$ as monotherapy and in combination compared to placebo and other antihyperglycemic agents [10, 11, 27-33]. Reported data has indicated that the probability of reaching target HbA1c $<7 \%$ is higher in the case of therapy with pioglitazone [34]. Pioglitazone has a manageable safety profile but remains associated with weight gain and edema [35]. Nevertheless, pioglitazone is not the drug of choice for many clinicians.

The main aim of our meta-analysis was to follow up changes in metabolic parameters and to evaluate the influence of pioglitazone on the glycemic and lipid profile of patients with T2DM. We reviewed a large number of 


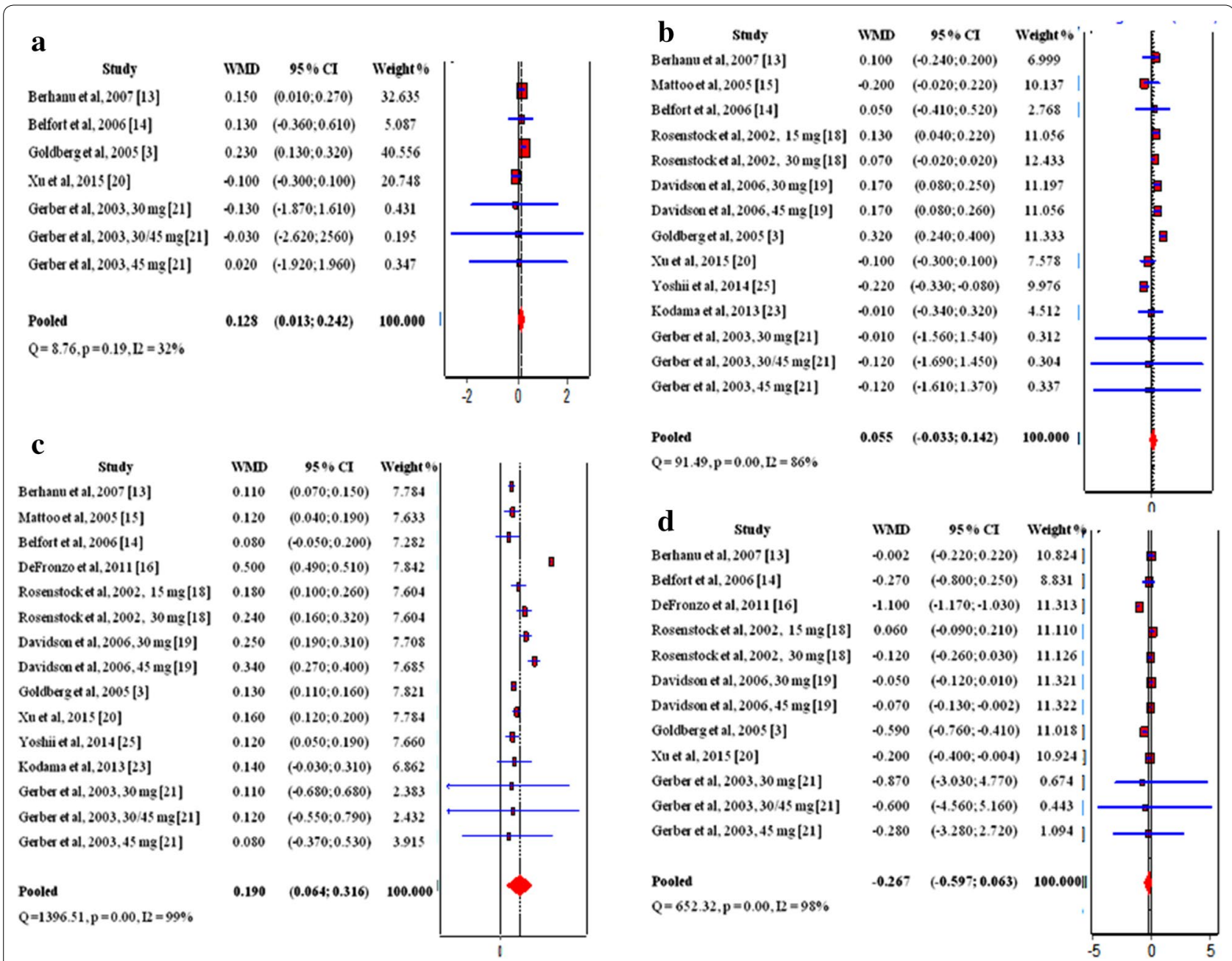

Fig. 3 Influence of pioglitazone on the lipid profile in T2DM patients, a influence of pioglitazone on the TC; $\mathbf{b}$ influence of pioglitazone on the LDL; c influence of pioglitazone on the HDL; $\mathbf{d}$ influence of pioglitazone on theTGs

sources and based our conclusions on articles we deemed to be of satisfactory quality.

Our results indicated that pioglitazone use was associated with positive effect on the glycemic profile with significant reductions in FPG and HbA1c (see Fig. 1a, b). Comparison with other sources showed consistency of our findings with published results. For example Lu et al. [27] and Scherbaum et al. [28] reported statistically significant reductions of FPG and HbA1c of around - 1.48 to $-2 \mathrm{mmol} / \mathrm{l}$ and -0.92 to $-1.05 \%$ respectively when pioglitazone therapy was compared to placebo. Other authors have reported similar or even larger reductions in FPG and HbA1c registered when pioglitazone treatment was compared to other antidiabetic drugs as monotherapy or in combination. Russel-Jones et al. [10] reported reductions of $-2.6 \mathrm{mmol} / \mathrm{l}$ and $-1.63 \%$ for FPG and HbA1c respectively with pioglitazone against treatment with sitagliptin, metformin or exenatide. When pioglitazone treatment was combined with the use of metformin, reductions of FPG and $\mathrm{HbA1c}$ were $-1.7 \mathrm{mmol} / \mathrm{l}$ and - $0.74 \%$ respectively, according to Chawla et al. [30]. Same authors reported decrease of FPG with sitagliptin/metformin combination of $-1.1 \mathrm{mmol} / \mathrm{l}$ suggesting more pronounced effect of pioglitazone despite the lack of statistical significance of the between group difference. Kaur et al. [36] concluded that pioglitazone combined with metformin and sulphonylurea produced a greater reduction in $\mathrm{HbAlc}$ and the results were statistically significant.

Apart from the achievement of a satisfactory glycemic profile and improvement of the insulin sensitivity pioglitazone use is known to be associated with the amelioration of dyslipidemia in patients with $\mathrm{T} 2 \mathrm{DM}[3,37]$. Khan et al. [38] performed an open-label, randomized 


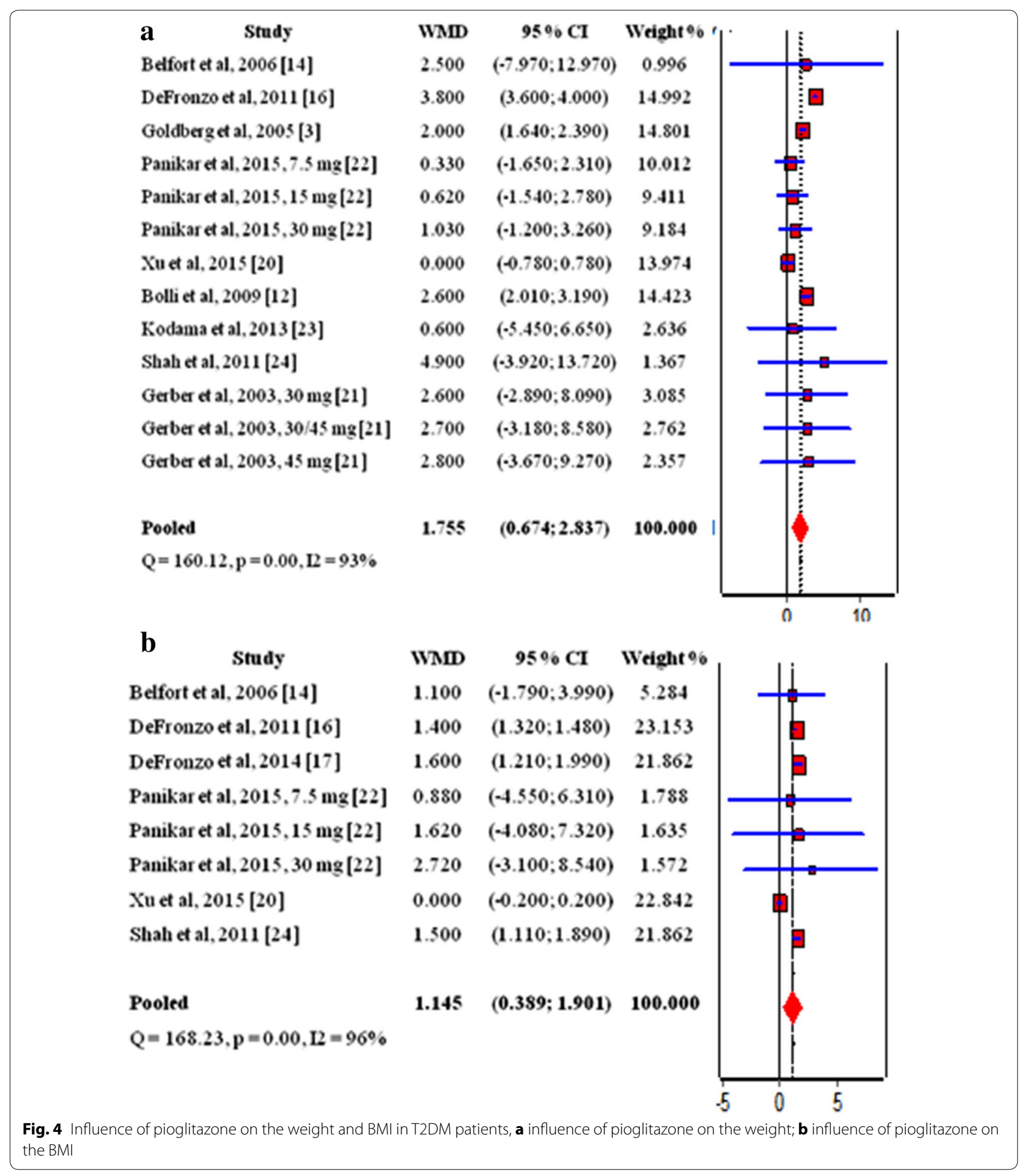

comparison of rosiglitazone and pioglitazone in patients previously treated with troglitazone. In that study, conversion to pioglitazone was associated with significant improvements in all lipid parameters. In a retrospective review of randomly selected medical records, it was shown that treatment with PIO was associated with greater beneficial effects on blood lipid profile with a reduction in mean TGs of $0.62 \mathrm{mmol} / \mathrm{l}$, a reduction in TC of $0.22 \mathrm{mmol} / \mathrm{l}$, an increase in $\mathrm{HDL}$ of $0.068 \mathrm{mmol} / \mathrm{l}$, and a reduction in LDL-C of $0.13 \mathrm{mmol} / \mathrm{l}$ [39]. 


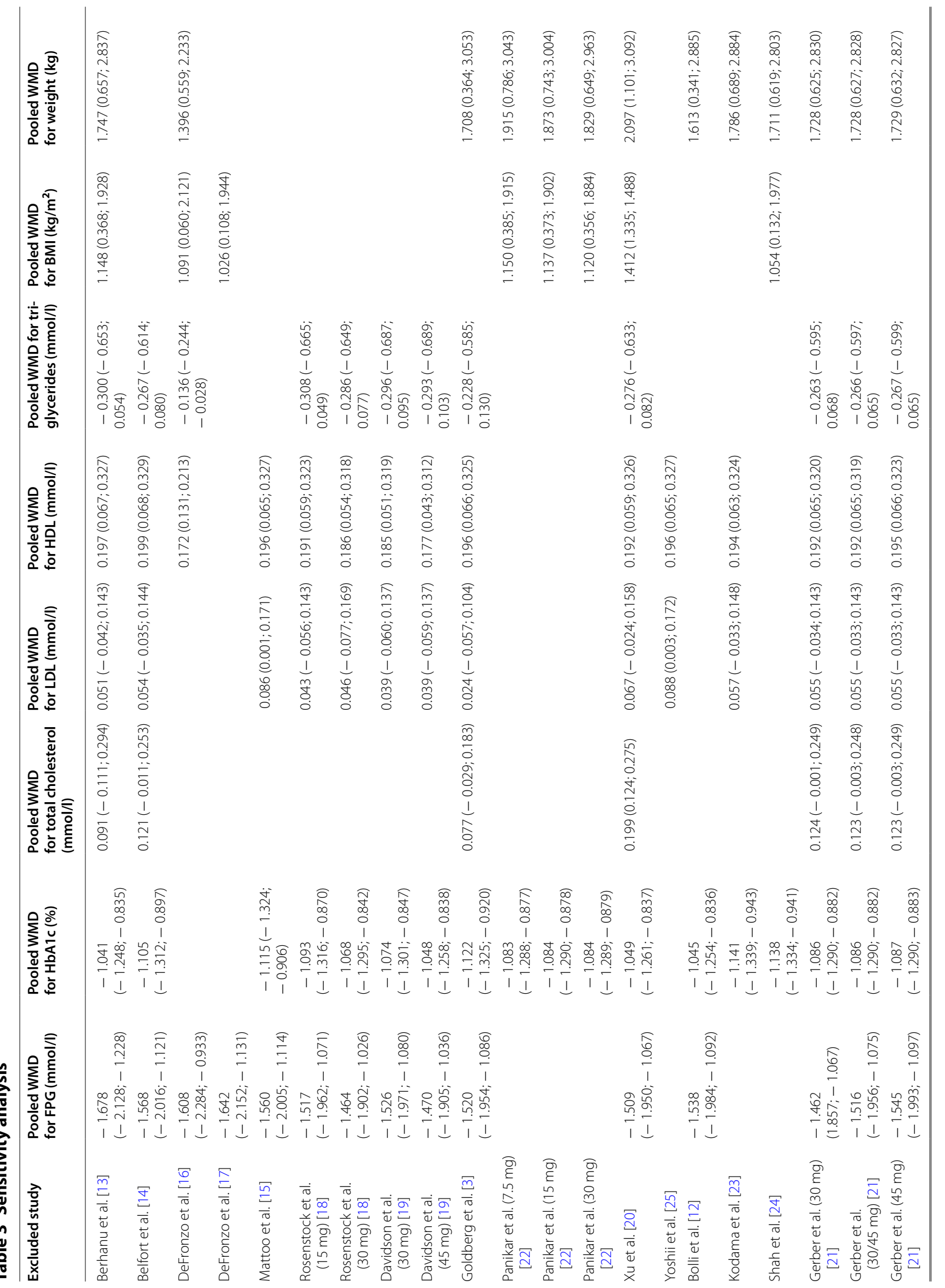


In contrast to the aforementioned benefits, the TZDs, in particular pioglitazone increased body weight $[9-12,31]$ in part because of differentiation of adipocytes and expansion of adipocyte mass. Activation of PPAR- $\gamma$ stimulates differentiation to insulin-sensitive smaller adipocytes and redistributes fat from visceral to subcutaneous depots, a pattern that has been associated with lower cardiovascular disease (CVD) risk. A recent meta-analysis incorporating results from 10 randomised trials concludes that pioglitazone lowers the risk of recurrent major adverse cardiovascular events, stroke, or myocardial infarction in patients with clinical manifest vascular disease [40]. A critical and updated overview of the main glucose-lowering agents and their risk/benefit ratio for the prevention of CVD in patients with T2DM speaks in favour of the positive effect of pioglitazone on the lipid profile and its ability to reduce the CVD risk [41]. Pioglitazone treatment also reduces visceral fat and decrease liver-fat resulting in increased insulin sensitivity in these tissues [23, 24].

Our study has limitations which are mainly connected with the degree of differentiation of parameters estimated in the studies included in the analysis. This is supposedly one of the reasons for the heterogeneity that we noted. Other factors it could be attributed to are the variation in the duration of therapies, different aspects of studies, difference in the antidiabetic drug experience of patients and the type of anidiabetic drugs used concomitantly with pioglitazone. We did not have individual patient data and therefore could not evaluate other factors that could potentially influence the glycemic or lipid profile.

\section{Conclusion}

Many clinicians worldwide are inclined to avoid pioglitazone use for the treatment of patients with T2DM. By summarizing and analyzing data from numerous trials we have been able to highlight the beneficial and unambiguous effect of pioglitazone on the glycemic profile, characterized by considerable reductions in the FPG and HbA1c. Another positive trend that we have determined is the improvement of the lipid balance. These conclusions are not contradictory to what has already been published by other authors and are a prerequisite for wider application of pioglitazone in the clinical practice. The only drawback we estimated was the increase of BMI and weight in patients with T2DM although we believe it should not discourage clinicians to provide diabetes patients the opportunity to exploit the benefits of the antihyperglycemic medication pioglitazone.

\section{Additional file}

Additional file 1: Figure S1. Funnel plot for FPG. Figure S2. Funnel lot for HbA1c. Figure S3. Funnel plot for total cholesterol. Figure S4. Funnel plot for LDL. Figure S5. Funnel plot for HDL. Figure S6. Funnel plot for TGs. Figure S7. Funnel plot for weight. Figure S8. Funnel plot for BMI.

\section{Abbreviations}

T2DM: type 2 diabetes mellitus; TZDs: thiazolidinediones; PPARY: peroxisome proliferator-activated receptors gamma; $\mathrm{HbA}_{1}$ : glycated hemoglobin; FPG: fasting plasma glucose; $\mathrm{HDL}$ : high-density lipoprotein; LDL: low-density lipoprotein; TGs: triglycerides; TC: total cholesterol; BMl: body mass index; WMD: weighted mean difference; CVD: cardiovascular disease; Cl: confidence interval.

\section{Authors' contributions}

$\mathrm{EF}, \mathrm{KU}$ and TV were involved in the literature search and initial selection of studies. KK performed statistical analysis. EF, KU, KK and TV were involved in the interpretation of results. All authors read and approved the final manuscript.

\section{Author details}

${ }^{1}$ Science Department, Tchaikapharma High Quality Medicines Inc., 1 G.M. Dimitrov Blvd, 1172 Sofia, Bulgaria. ${ }^{2}$ Department of Informatics, New Bulgarian University, 21 Montevideo Str, 1618 Sofia, Bulgaria. ${ }^{3}$ Faculty of Pharmacy, Medical University, Pleven, Bulgaria.

\section{Acknowledgements}

The authors would like to thank Vladimir Tochev for providing support with English language editing.

\section{Competing interests}

KU and EF are employees of Tchaikapharma High Quality Medicines Inc. KK and TV have no competing interests to declare.

\section{Availability of data and materials}

All data generated or analysed during this study are included in this published article and its additional information files (Additional file 1).

\section{Consent for publication}

Not applicable.

Ethics approval and consent to participate

Not applicable.

Funding

Tchaikapharma High Quality Medicines Inc funded the preparation of this meta-analysis.

\section{Publisher's Note}

Springer Nature remains neutral with regard to jurisdictional claims in published maps and institutional affiliations.

Received: 21 July 2017 Accepted: 2 November 2017

Published online: 14 November 2017

\section{References}

1. WHO "Data and statistics". http://www.euro.who.int/en/health-topics/ noncommunicable-diseases/diabetes/data-and-statistics. Accessed 20 Jan 2016.

2. Haffner SM, D'Agostino R Jr, Mykkänen L, Tracy R, Howard B, Rewers M, et al. Insulin sensitivity in subjects with type 2 diabetes. Relationship to cardiovascular risk factors: the insulin resistance atherosclerosis study. Diabetes Care. 1999;22(4):562-8. 
3. Goldberg RB, Kendall DM, Deeg MA, Buse JB, Zagar AJ, Pinaire JA, et al. GLAI Study Investigators. A comparison of lipid and glycemic effects of pioglitazone and rosiglitazone in patients with type 2 diabetes and dyslipidemia. Diabetes Care. 2005;28(7):1547-54.

4. Siegel RD, Cupples A, Schaefer EJ, Wilson PW. Lipoproteins, apolipoproteins, and low-density lipoprotein size among diabetics in the Framingham offspring study. Metabolism. 1996;45(10):1267-72.

5. Nesto RW. Correlation between cardiovascular disease and diabetes mellitus: current concepts. Am J Med. 2004;8(116 Suppl 5A):11S-22S.

6. Lehmann JM, Moore LB, Smith-Oliver TA, Wilkison WO, Willson TM, Kliewer SA. An antidiabetic thiazolidinedione is a high affinity ligand for peroxisome proliferator-activated receptor gamma (PPAR gamma). J Biol Chem. 1995;270:12953-6.

7. Charbonnel B, Roden M, Urquhart R, Mariz S, Johns D, Mihm M, et al. Pioglitazone elicits long-term improvements in insulin sensitivity in patients with type 2 diabetes: comparisons with gliclazide-based regimens. Diabetologia. 2005;48:553-60.

8. Krishnaswami A, Ravi-Kumar S, Lewis JM. Thiazolidinediones: a 2010 perspective. Perm J. 2010;14(3):64-72.

9. Jindal A, Kaur R, Jindal M. Comparative study: Efficacy and tolerability of vildagliptin vs. pioglitazone as an add-on therapy to metformin in poorly controlled type 2 diabetes mellitus patients in Punjab. IAIM. 2015;2(1):83-94.

10. Russell-Jones D, Cuddihy RM, Hanefeld M, Kumar A, González JG, Chan $M$, et al. Efficacy and safety of exenatide once weekly versus metformin, pioglitazone, and sitagliptin used as monotherapy in drug-naive patients with type 2 diabetes (DURATION-4): a 26-week double-blind study. Diabetes Care. 2012;35(2):252-8.

11. Rosenstock J, Kim SW, Baron MA, Camisasca RP, Cressier F, Couturier A, et al. Efficacy and tolerability of initial combination therapy with vildagliptin and pioglitazone compared with component monotherapy in patients with type 2 diabetes. Diabetes Obes Metab. 2007:9(2):175-85.

12. Bolli G, Dotta F, Colin L, Minic B, Goodman M. Comparison of vildagliptin and pioglitazone in patients with type 2 diabetes inadequately controlled with metformin. Diabetes Obes Metab. 2009;1 1(6):589-95.

13. Berhanu P, Perez A, Yu S, Spanheimer R. Effect of pioglitazone in combination with insulin therapy on glycaemic control, insulin dose requirement and lipid profile in patients with type 2 diabetes previously poorly controlled with combination therapy. Diabetes Obes Metab. 2007;9(4):512-20.

14. Belfort R, Harrison SA, Brown K, Darland C, Finch J, Hardies J, et al. A placebo-controlled trial of pioglitazone in subjects with nonalcoholic steatohepatitis. N Engl J Med. 2006;355(22):2297-307.

15. Mattoo V, Eckland D, Widel M, Duran S, Fajardo C, Strand J, et al. H6EMC-GLAT study group. Metabolic effects of pioglitazone in combination with insulin in patients with type 2 diabetes mellitus whose disease is not adequately controlled with insulin therapy: results of a 6-month, randomized, double-blind, prospective, multicenter, parallel-group study. Clin Ther. 2005;27(5):554-67.

16. DeFronzo RA, Tripathy D, Schwenke DC, Banerji M, Bray GA, Buchanan TA, et al, ACT NOW Study. Pioglitazone for diabetes prevention in impaired glucose tolerance. NEnglJ Med. 2011;364(12):1104-15.

17. Defronzo RA, Tripathy D, Abdul-Ghani M, Musi N, Gastaldelli A. The disposition index does not reflect $\beta$-cell function in IGT subjects treated with pioglitazone. J Clin Endocrinol Metab. 2014;99(10):3774-81.

18. Rosenstock J, Einhorn D, Hershon K, Glazer NB, Yu S. Efficacy and safety of pioglitazone in type 2 diabetes: a randomized, placebocontrolled study in patients receiving stable insulin therapy. IJCP. 2002;56(4):251-7

19. Davidson JA, Perez A, Zhang J. Addition of pioglitazone to stable insulin therapy in patients with poorly controlled type 2 diabetes: results of a double-blind, multicentre, randomized study. Diab Obes Metab. 2006:8:164-74.

20. Xu W, Bi Y, Sun Z, Li J, Guo L, Yang T, et al. Comparison of the effects on glycaemic control and $\beta$-cell function in newly diagnosed type 2 diabetes patients of treatment with exenatide, insulin or pioglitazone: a multicentre randomized parallel-group trial (the CONFIDENCE study). J Intern Med. 2015;277(1):137-50.

21. Gerber P, Lübben G, Heusler S, Dodo A. Effects of pioglitazone on metabolic control and blood pressure: a randomised study in patients with type 2 diabetes mellitus. Curr Med Res Opin. 2003;19(6):532-9.

22. Panikar V, Kale NJ, Hoskote SS, Deogaonkar N, Joshi SR. Effect of low ( $7.5 \mathrm{mg} / \mathrm{day})$, standard ( $15 \mathrm{mg} /$ day) and high ( $30 \mathrm{mg} /$ day) dose pioglitazone therapy on glycemic control and weight gain in recently-diagnosed type 2 diabetes patients. J Assoc Physicians India. 2015:63(November):36-9.

23. Kodama N, Tahara N, Tahara A, Honda A, Nitta Y, Mizoguchi M, et al. Effects of pioglitazone on visceral fat metabolic activity in impaired glucose tolerance or type 2 diabetes mellitus. J Clin Endocrinol Metab. 2013;98(11):4438-45.

24. Shah PK, Mudaliar S, Chang AR, Aroda V, Andre M, Burke P, et al. Effects of intensive insulin therapy alone and in combination with pioglitazone on body weight, composition, distribution and liver fat content in patients with type 2 diabetes. Diabetes Obes Metab. 2011;13(6):505-10.

25. Yoshii H, Onuma T, Yamazaki T, Watada H, Matsuhisa M, Matsumoto M, et al. Effects of pioglitazone on macrovascular events in patients with type 2 diabetes mellitus at high risk of stroke: the PROFIT-J study. J Atheroscler Thromb. 2014;21(6):563-73.

26. Banerjee S. Pioglitazone safe. So safe. JAPI. 2012;60:62-6.

27. Lü ZH, Pan CY, Gao Y, Guo LX, Ning G, Liu ZM, et al. A randomized, double blind, placebo-controlled, parallel and multicenter study to evaluate the safety and efficacy of pioglitazone with sulphonylurea in type 2 diabetic patients. Zhonghua Nei Ke Za Zhi. 2011;50(10):826-30.

28. Scherbaum WA, Göke B. German pioglitazone study group. Metabolic efficacy and safety of once-daily pioglitazone monotherapy in patients with type 2 diabetes: a double-blind, placebo-controlled study. Horm Metab Res. 2002;34(10):589-95.

29. Pérez-Monteverde A, SeckT, Xu L, Lee MA, Sisk CM, Williams-Herman DE, et al. Efficacy and safety of sitagliptin and the fixed-dose combination of sitagliptin and metformin vs. pioglitazone in drug-naïve patients with type 2 diabetes. Int J Clin Pract. 2011;65(9):930-8.

30. Chawla S, Kaushik N, Singh NP, Ghosh RK, Saxena A. Effect of addition of either sitagliptin or pioglitazone in patients with uncontrolled type 2 diabetes mellitus on metformin: a randomized controlled trial. J Pharmacol Pharmacother. 2013;4(1):27-32.

31. Liu SC, Chien KL, Wang CH, Chen WC, Leung CH. Efficacy and safety of adding pioglitazone or sitagliptin to patients with type 2 diabetes insufficiently controlled with metformin and a sulfonylurea. Endocr Pract. 2013;19(6):980-8.

32. Bergenstal RM, Wysham C, Macconell L, Malloy J, Walsh B, Yan P, et al. Efficacy and safety of exenatide once weekly versus sitagliptin or pioglitazone as an adjunct to metformin for treatment of type 2 diabetes (DURATION-2): a randomised trial. Lancet. 2010;376(9739):431-9.

33. Lee YK, Song SO, Kim KJ, Cho Y, Choi Y, Yun Y, et al. Glycemic effectiveness of metformin-based dual-combination therapies with sulphonylurea, pioglitazone, or DPP-4-inhibitor in drug-naïve Korean type 2 diabetic patients. Diabetes Metab J. 2013;37(6):465-74.

34. Karagiannis T, Paschos P, Paletas K, Matthews DR, Tsapas A. Dipeptidyl peptidase-4 inhibitors for treatment of type 2 diabetes mellitus in the clinical setting: systematic review and meta-analysis. BMJ. 2012;344:e1369.

35. McGuire DK, Inzucchi SE. New drugs for the treatment of diabetes mellitus: part I: thiazolidinediones and their evolving cardiovascular implications. Circulation. 2008;117(3):440-9.

36. Kaur K, Kaur R, Mittal N, Arora S, Kaushal S. Comparison of efficacy of addon therapy of vildagliptin versus pioglitazone among type 2 diabetes mellitus patients inadequately controlled on dual therapy of metformin plus sulfonylurea. Asian J Med Sci. 2014;5(3):77-81.

37. van Wijk JP, de Koning EJ, Martens EP, Rabelink TJ. Thiazolidinediones and blood lipids in type 2 diabetes. Arterioscler ThrombVasc Biol. 2003;23:1744-9.

38. Khan MA, St Peter JV, Xue JL. A prospective, randomized comparison of the metabolic effects of pioglitazone or rosiglitazone in patients with type 2 diabetes who were previously treated with troglitazone. Diabetes Care. 2002;25:708-11.

39. Boyle PJ, King AB, Olansky L, Marchetti A, Lau H, Magar R, et al. Effects of pioglitazone and rosiglitazone on blood lipid levels and glycemic control in patients with type 2 diabetes mellitus: a retrospective review of randomly selected medical records. Clin Ther. 2002;24:378-96. 
40. de Jong $\mathrm{M}$, van der Worp HB, van der Graaf Y, Visseren FLJ, Westerink J. Pioglitazone and the secondary prevention of cardiovascular disease. A meta-analysis of randomized-controlled trials. Cardiovasc Diabetol. 2017;16(1):134.
41. Paneni F, Lüscher TF. Cardiovascular protection in the treatment of type 2 diabetes: a review of clinical trial results across drug classes. Am J Cardiol. 2017;120(1S):S17-27.
Submit your next manuscript to BioMed Central and we will help you at every step:

- We accept pre-submission inquiries

- Our selector tool helps you to find the most relevant journal

- We provide round the clock customer support

- Convenient online submission

- Thorough peer review

- Inclusion in PubMed and all major indexing services

- Maximum visibility for your research

Submit your manuscript at www.biomedcentral.com/submit 